\title{
Epistemologia e teorias da educação
}

Régis Henrique dos Reis Silva

Editor do dossiê Epistemologia e Teorias da Educação

Márcia Chaves-Gamboa

Sarah Maria de Freitas Machado Silva

Coordenadoras do IV Seminário de Epistemologia e Teorias da Educação

Editoras do dossiê Epistemologia e Teorias da Educação

N

esta edição da revista Filosofia e Educação apresentamos aos leitores mais um dossiê sobre Epistemologia e Teorias da Educação. Passados

dois anos da primeira edição da temática citada, esta é retomada sob a

perspectiva da análise da produção do conhecimento em Educação e Educação Física, com destaque para a questão das teorias e métodos. Essa opção não foi casual, pois resultante de mais um Seminário de Epistemologia e Teorias da Educação (EPISTED). Tratou-se do quarto evento organizado pela linha Epistemologia e Teorias da Educação, em conjunto com as demais linhas de pesquisa do Grupo de Estudos e Pesquisas em Filosofia e Educação (Paideia) da Universidade Estadual de Campinas e da Secretaria Paulista do Colégio Brasileiro de Ciências do Esporte (CBCE/SP).

Os eventos denominados Seminários de Epistemologia e Teorias da Educação (EPISTEDs) justificam-se no contexto da consolidação das linhas de pesquisa do Programa de Pós-graduação da Faculdade de Educação (FE) da Unicamp. O Programa está dividido em 6 áreas ${ }^{1}$, dentre elas a área 2, de Filosofia e História da Educação. A produção dessa área, integrada pelos grupos Paideia e HistEdBr (História, Sociedade e Educação no Brasil), vem sendo amplamente divulgada e discutida através de seminários temáticos periódicos.

O grupo Paideia se propôs iniciar essas atividades com um primeiro seminário sobre Epistemologia e Teorias da Educação, realizado nos dias 6 e 7 de dezembro de 2005. Na ocasião, a área de Filosofia e História da Educação registrava 378

1 O Programa de Pós-Graduação em Educação (PPGE) está organizado nas seguintes áreas temáticas: 1) Políticas, Administração e Sistemas Educacionais; 2) Filosofia e História da Educação; 3) Psicologia Educacional; 4) Ensino e Práticas Culturais; 5) Educação Conhecimento, Linguagem e Arte; 6) Ciências Sociais na Educação.

Filosofia e Educação (Online), ISSN 1984-9605 - Volume 5, Número 2, Outubro de 2013 
pesquisas defendidas, das quais 192 teses de doutorado e 186 dissertações de mestrado. Considerando apenas as teses defendidas, 100 localizavam-se na área de História e 92 na de Filosofia. Com base nessa primeira experiência foram organizados novos eventos que visavam sistematizar, analisar e socializar a produção científica da área 2, no intuito de manter um permanente debate sobre a problemática que a identifica, contando com a participação de outros grupos de pesquisa, tanto nacionais quanto estrangeiros.

A partir do II EPISTED (2006), considerando a conjuntura de campos comuns de pesquisa compartilhados com o Grupo de Trabalho Temático (GTT) de Epistemologia do Colégio Brasileiro de Ciências do Esporte (CBCE), propôs-se a realização dos seminários de forma integrada com os Colóquios de Epistemologia da Educação Física que vinham acontecendo desde 2002. Essa integração foi motivada pela constatação da significativa presença de mestres e doutores oriundos da Educação Física que produziam suas pesquisas no âmbito do grupo Paideia. Das 378 pesquisas defendidas até dezembro de 2005, 45 haviam sido dedicadas à problemática da Educação Física, seja na tentativa de fundamentação de uma filosofia da área, seja na reflexão sobre a história da Educação Física. A prévia definição dos temas centrais do II EPISTED possibilitou a realização de um evento conjunto, que correspondia ao III Colóquio de Epistemologia do GTT Epistemologia do $\mathrm{CBCE}$, sob a responsabilidade de membros dessa entidade vinculados a instituições paulistas. O III Colóquio, de forma semelhante aos dois primeiros colóquios realizados nas Universidades Federais (UFRN e UFPel), seria realizado também em conjunto com outros eventos paralelos. A articulação dos eventos permitiu otimizar recursos e desenvolver a perspectiva da interdisciplinaridade em torno de problemas comuns. Com base nessas condições, os representantes do Paideia e do GTT Epistemologia do CBCE elaboraram uma proposta articulada, encaminhada aos órgãos de fomento Fapesp e Faepex/Unicamp, que apoiaram o evento. 
O III EPISTED e o IV Colóquio de Epistemologia da Educação Física, realizados nos dias 09, 10 e 11 de dezembro de 2008, tiveram como tema central: Epistemologias, teorias do conhecimento na pesquisa em Educação e Educação Física: as reações aos pós-modernismos. Buscou-se, na ocasião, aprofundar uma temática já desenvolvida em conjunto com o GTT Epistemologia, valendo-se do apoio da Secretaria Estadual de São Paulo do CBCE sediada na FE/Unicamp. Particularmente a discussão sobre os "giros epistemológicos" e suas repercussões na pesquisa educacional havia sido trabalhada em mesas-redondas durante o XV Congresso Brasileiro de Ciências do Esporte, realizado em Recife em setembro de 2007. Tais tentativas de aprofundamento implicaram um olhar crítico sobre as diversas "viradas epistemológicas" (linguística, hermenêutica, pragmática e ontológica), uma retomada das teorias do conhecimento que fundamentam as pesquisas em Educação e Educação Física e uma atualização das controvérsias em torno dos pós-modernismos.

Nessa quarta edição do EPISTED, realizada nos dias 5, 6 e 7 de dezembro de 2012, procuramos inovar no processo de editoração e publicação dos trabalhos submetidos ao evento, ao utilizarmos o Sistema Online de Administração de Conferências (SOAC/OCS 2.3.4.0), sistema de código aberto para administração de conferências, desenvolvido e distribuído gratuitamente pelo Public Knowledge Project sob a General Public License. Ao mesmo tempo, procuramos fazer um balanço da repercussão dos 25 anos dos diferentes usos do Esquema Paradigmático, instrumental desenvolvido e utilizado pela primeira vez no Brasil pelo professor Sílvio A. Sánchez Gamboa, em tese defendida na FE/Unicamp em 1987. Em que pese a condição de todo trabalho datado, tal tese apresentou às áreas de Educação e afins uma rica contribuição de desenvolvimento teórico acerca da análise da produção acadêmica, pois possibilitou a reconstrução da lógica de desenvolvimento da pesquisa por meio das teorias e dos métodos, contribuindo dessa forma para a superação por incorporação da visão técnico-operacional que imperava nos cursos de formação de pesquisadores, assim como para a passagem

Filosofia e Educação (Online), ISSN 1984-9605 - Volume 5, Número 2, Outubro de 2013 
das discussões teórico-metodológicos às questões teórico-filosóficas implícitas no fazer científico da área de Educação e afins.

O IV EPISTED reuniu alunos de graduação e de pós-graduação, assim como pesquisadores oriundos de diversas universidades e grupos de pesquisa, socializando resultados de estudos e pesquisas sobre a problemática da epistemologia e das teorias da educação que sustentam a pesquisa em Educação e em Educação Física. O evento proporcionou um ambiente de interação entre pesquisadores interessados nos balanços da produção do conhecimento nas ciências humanas e sociais, deu visibilidade às pesquisas dos estudantes e docentes dos grupos de pesquisa interessados nos estudos da epistemologia e estabeleceu vínculos acadêmicos entre diferentes instituições e grupos de pesquisa, possibilitando a organização de redes de intercâmbio e o desenvolvimento de projetos integrados pela problemática epistemológica da pesquisa e da produção do conhecimento nas ciências humanas e sociais.

O evento desdobrou-se numa temática geral e em três temáticas centrais. A temática geral foi desenvolvida por meio da conferência de abertura, intitulada A produção do conhecimento em Educação: teorias e métodos, ministrada pelo professor doutor Sílvio A. Sánchez Gamboa (Unicamp) e debatida pelos professores doutores Alexandro Andrade (UDESC) e Carlos Jorge Paixão (UFPA).

As temáticas centrais foram discutidas em três mesas-redondas. A primeira, denominada Análise da produção científica sob a perspectiva bibliométrica e cientométrica, foi realizada pelo grupo de pesquisa Ciência, Tecnologia e Sociedade da UFSCar e ministrada pelos professores doutores Carlos Roberto Massao Hayashi (UFSCar), Maria Cristina Piumbato Innocentini Hayashi (UFSCar) e Márcia Regina da Silva (USP). A segunda, intitulada Análise da produção científica: perspectivas interdisciplinares, foi organizada pelo Grupo LEPEL/UFBA, contando com as professoras doutoras Elza Margarida de Mendonça Peixoto (UFBA), Kátia Oliver de Sá (Unicamp) e Joelma de Oliveira Albuquerque (UFAL). A terceira mesa-redonda, Pressupostos filosóficos das novas diretrizes 
curriculares da educação básica no Brasil, foi promovida pelo Paideia, com a participação dos professores doutores César Apareciddo Nunes e Sílvio Gallo.

Registrando a presença de mais de uma centena de pesquisadores, o IV EPISTED constituiu para eles a oportunidade e o espaço para a apresentação de 54 trabalhos científicos, dos quais 25 na forma de pôsteres e 29 na de comunicações orais. Todos eles, tanto no formato de resumos quanto no de trabalhos completos, encontram-se publicados no Portal de Eventos da FE, que pode ser acessado no seguinte endereço virtual: http://www.fae.unicamp.br/eventos/index.php/episted/EPISTED.

A presente edição de Filosofia e Educação traz os textos produzidos por palestrantes da conferência de abertura e das mesas temáticas, bem como por autores de trabalhos que foram convidados a participar deste dossiê. Dos 16 artigos ora publicados, sete são de autoria dos palestrantes/debatedores, nove de participantes convidados e um foi submetido à revista e aprovado por dois pareceristas, conforme a praxe.

Os leitores têm acesso à temática geral do evento mediante os seguintes artigos: Evolução da análise da produção do conhecimento em Educação e Educação Física: a dialética de um espectador (1987-2012), de Silvio A. Sánchez Gamboa, Pós-Graduação em educação física, inovação e prática pedagógica: reflexões iniciais, de Alexandro Andrade, e Episteme dos Métodos, de Carlos Jorge Paixão. À mesa-redonda Análise da produção científica sob a perspectiva bibliométrica e cientométrica vinculam-se os artigos Afinidades eletivas entre a cientometria e os estudos sociais da ciência, de Maria Cristina Piumbato Innocentini Hayashi, Apontamentos sobre a coleta de dados em estudos bibliométricos e cientométricos, de Carlos Roberto Massao Hayashil, e A documentalidade das citações bibliográficas, de autoria de Márcia Regina da Silva e Solange Puntel Mostafa. Já o texto Interdisciplinaridade e análise da produção científica: apontamentos a partir da concepção materialista e dialética da história, de Elza Margarida de Mendonça Peixoto, pertence à mesa Análise da produção científica: perspectivas interdisciplinares. 
Oito artigos foram apresentados originalmente como comunicações: Balanço tendencial das dissertações e teses sobre dificuldades de aprendizagem (1987-2010), de José Geraldo Silveira Bueno e Angelita Mendes Ramos de Oliveira; Cosmovisão, educação e diversidade étnica para a emancipação Xokleng/la klãnõ, de Vania Konell e Carlos Odilon da Costa; Aproximações ao pressuposto absoluto da Educação com relação ao conceito de desconstrução de Derrida, de Artur José Renda Vitorino; A episteme e a opinião no projeto pedagógico de Platão, de Terezinha Duarte Vieira; Corpo e Educação Física: indicadores de produção científica, de autoria de Michele Silva Sacardo, Janaina Walkíria Brito e Silva, Laylianne Torres Fernandes de Souza e Liliane Alcântara; Análise da produção do conhecimento: pesquisa em rede com base no materialismo histórico dialético, de Kátia Oliver de Sá, Ivson Conceição Silva e Gilson Trindade dos Santos; A condição histórico-social da mulher na perspectiva socialista: um estudo das trajetórias de Rosa Luxemburgo e Alexandra Kollontai, de Cláudia Ramos de Souza Bonfim; Crítica à pesquisa em educação do campo no Brasil: o limite crítico entre a educação do campo e a educação rural, de Joelma de Oliveira Albuquerque.

Por sua vez, Dewey e Dennett - Dos fundamentos do naturalismo evolutivo aos fundamentos da educação, de José Claudio Morelli Matos, publicado na seção Artigos, resulta do processo regular de submissão, avaliação e aprovação por pares da revista Filosofia e Educação.

Acreditamos que os leitores têm em mãos um material de consulta e de pesquisa que contribui significativamente para dilatar o avanço dos conhecimentos sobre a Educação e a Educação Física no Brasil, justificando os esforços promovidos pelos organizadores dos IV EPISTED no sentido de socializar os resultados dos trabalhos que vêm sendo realizados nas referidas áreas.

Filosofia e Educação (Online), ISSN 1984-9605 - Volume 5, Número 2, Outubro de 2013 